\title{
Development of Molecular Marker to Detect Citrus Melanose Caused by Diaporthe citri from Citrus Melanose-like Symptoms
}

\author{
Cheol-Woo Choi, Kyung-Eun Jung, Min-Ju Kim, Su-Hyeon Yoon, Suk-Man Park, Seong-Beom Jin, \\ and Jae-Wook Hyun* \\ Citrus Research Institute, National Institute of Horticultural \& Herbal Science, Rural Development Administration, Jeju \\ 63607, Korea
}

(Received on July 22, 2021; Revised on October 22, 2021; Accepted on October 24, 2021)

It is difficult to distinguish melanose and melanoses-like symptoms with the naked eye because they appear similar. To accurately detect melanose symptoms caused by Diaporthe citri from melanose-like symptoms, we developed PCR-based specific primers Dcitri by aligning the internal transcribed spacer (ITS) region of $D$. citri with the ITS of Diaporthe cytosporella, Diaporthe foeniculina, Colletotrichum gloeosporioides, Botrytis cinerea, Alternaria citri, and Fusarium oxysporum found on citrus peel. PCR results showed that the specific product was amplified in $D$. citri but not in other isolates including, $C$. gloeosporioides, B. cinerea, $A$. citri, $F$. oxysporum. In addition, specific products were observed in melanose symptoms caused by $D$. citri but not in melanose-like symptoms, such as copper-injury, sunscald, damages by yellow tea thrips, and pink citrus rust mite. Using the Dcitri primers developed in this study, it is expected that melanose caused by $D$. citri could be accurately distinguished from melanose-like symptoms.

Keywords : citrus, detection, melanose

*Corresponding author.

Phone) +82-64-730-4101

E-mail) hyunjaewook@korea.kr

Handling Editor : Junhyun Jeon

(c) This is an Open Access article distributed under the terms of the Creative Commons Attribution Non-Commercial License (http:// creativecommons.org/licenses/by-nc/4.0) which permits unrestricted noncommercial use, distribution, and reproduction in any medium, provided the original work is properly cited.

Articles can be freely viewed online at www.ppjonline.org.
Citrus melanose disease caused by Diaporthe citri is one of the major citrus diseases (Hyun et al., 2013). Melanose does not affect the pulp quality of fruit but damages the surface of the rind, reducing fruit quality and marketability. Melanose on citrus tree infects all tissues, including leaves, twigs, and fruits, and most citrus species are susceptible to it (Gopal et al., 2014).

Inoculums of $D$. citri were produced from dead twigs, and fungal spore production with pathogenic $\alpha$ type and non-pathogenic $\beta$ type were affected by environmental conditions such as the temperature and rainfall conditions in the orchard. To prevent damage caused by melanose, mancozeb is sprayed in most citrus orchards from midJune to late August or mid-September (Yi et al., 2014).

Melanose symptoms vary depending on severity. In mild conditions, the symptoms were scattered black spots; each spot in the center was depressed and surrounded by yellow areas. Under severe conditions, the symptoms spread widely on the surface of fruits with flowing water and appear as solid patches of blemish, forming a tear-drop or mudcakelike pattern (Whiteside and Timmer, 2000).

It is sometimes difficult to distinguish melanose and melanoses-like symptoms with the naked eye because they appear similar. Copper and zinc injuries on fruits resembled initial melanose symptoms. Copper sprays, such as bordeaux, are protectant fungicides and are used to control citrus diseases, such as melanose, mainly citrus canker caused by Xanthomonas citri subsp. citri, and scab disease caused by Elsinoe fawcettii, before disease infection. When spraying copper fungicide at higher concentrations (Albrigo and Grosser et al., 1996) or spraying in hot weather, the risk of copper damage can increase on leaves and fruits (Hyun et al., 2005). Zinc is a micro-element applied via spraying when citrus shows signs of zinc deficiency. When more than $0.3 \%$ zinc sulfate is sprayed only, the leaves or fruits 
might be damaged. Copper and zinc damage symptoms are stippling of leaves and fruits owing to spray, and are similar to the scattered black spots of melanose symptoms caused by $D$. citri.

Some other injuries on fruits are similar to the late-stage symptoms of melanose. Yellow tea thrips, Scirtothrips dorsalis hood, and pink citrus rust mite, Aculops pelekassi keifer, are also serious insects in citrus orchards. Once these insects feed on the rind of fruits, their surfaces become dead, rusty, and black (Childers and Achor, 1999; Hyun et al., 2012). Sunscald injury on fruits is caused by high temperature or high intensive solar radiation. Symptoms on fruits vary from yellow to brownish superficial blemishes with necrotic dark spots (Barber and Sharpe, 1971).

The melanose-symptomatic fruits of haryejosaeng, citrus unshiu, and melanose-like symptoms caused by copper spray were observed with the naked eye and a stereo microscope using Zeiss SteREO Discovery. V20 (Zeiss, Göttingen, Germany). To induce copper-injury on fruit, 4 g per liter of copper sulfate $\left(\mathrm{CuSO}_{4} \cdot \mathrm{H}_{2} \mathrm{O}\right)$ mixed with paraffin oil, twice the concentration of the standard protocol, was sprayed on the fruits of the haryejosaeng in the open research field. After 3 days, copper-injury on fruits was observed and collected. In melanose-symptomatic fruits, typical symptoms show scattered black spots, depressed in the center of lesions, and surrounded by yellow areas (Fig. 1A and B). Similar symptoms of melanose were also observed in copper injury on fruits (Fig. 1C and D).

We observed late-stage symptoms of melanose on fruits (Fig. 2A-C), late-stage symptoms on fruits damaged by yellow tea thrips (Fig. 2D-F) and pink rust mite (Fig. 2G-
I) from environmentally friendly orchards. The symptoms on fruits caused by sunscald (Fig. 2J and K) were observed in the research greenhouse of the Citrus Research Institute (CRI).

To design specific marker for $D$. citri, the internal transcribed spacer region (ITS) sequence of D. citri was cloned and then the specific primers were determined by comparison with the ITS of other Diaporthe spp., such as Diaporthe cytosporella and Diaporthe foeniculina (Udayanga et al., 2014), Colletotrichum gloeosporioides, Botrytis cinerea, Altanaria citri, and Fusarium spp. found on citrus fruits. D. citri was isolated in CRI as described previously (Kwon et al., 2003).

To extract genomic DNA from these isolates, D. citri grown on oatmeal agar $(60.0 \mathrm{~g}$ of oatmeal and $12.5 \mathrm{~g}$ of agar in 1 liter of distilled water) and $C$. gloeosporioides, B. cinerea, A. citri, and Fusarium spp. on potato dextrose agar (potato dextrose agar; $12.0 \mathrm{~g}$ of oatmeal and $15 \mathrm{~g}$ of agar in 1 liter of distilled water) were harvested at 7 days and then ground with sterilized mortars and pestles in liquid nitrogen. All homogenized samples were stored at $-20^{\circ} \mathrm{C}$ until genomic DNA extraction. Total genomic DNA was extracted using the Qiagen DNeasy mini kit standard protocol (Qiagen, Germantown, MD, USA) following the standard protocol. Finally, genomic DNA samples were eluted in $100 \mu \mathrm{l}$ of elution buffer and stored at $-20^{\circ} \mathrm{C}$. The ITS sequence of $D$. citri was cloned and sequenced. The ITS primers (Table 1) amplified a product of $604 \mathrm{bp}$ from $D$. citri and then, the product was eluted from a $1 \%$ agarose gel using a QIAquick Gel Extraction Kit (Qiagen), cloned, and transformed using the Topo TA Cloning
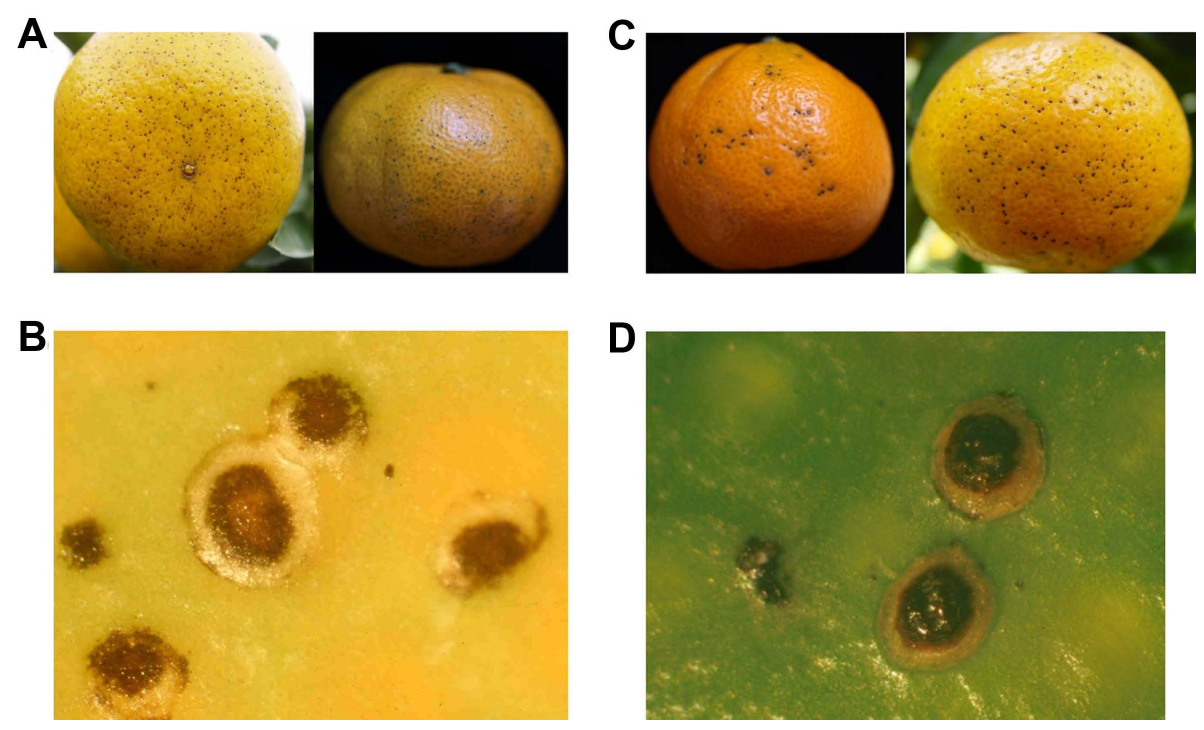

Fig. 1. Symptoms of citrus melanoses diseases (A, B) and damaged by copper sprays (C, D). 

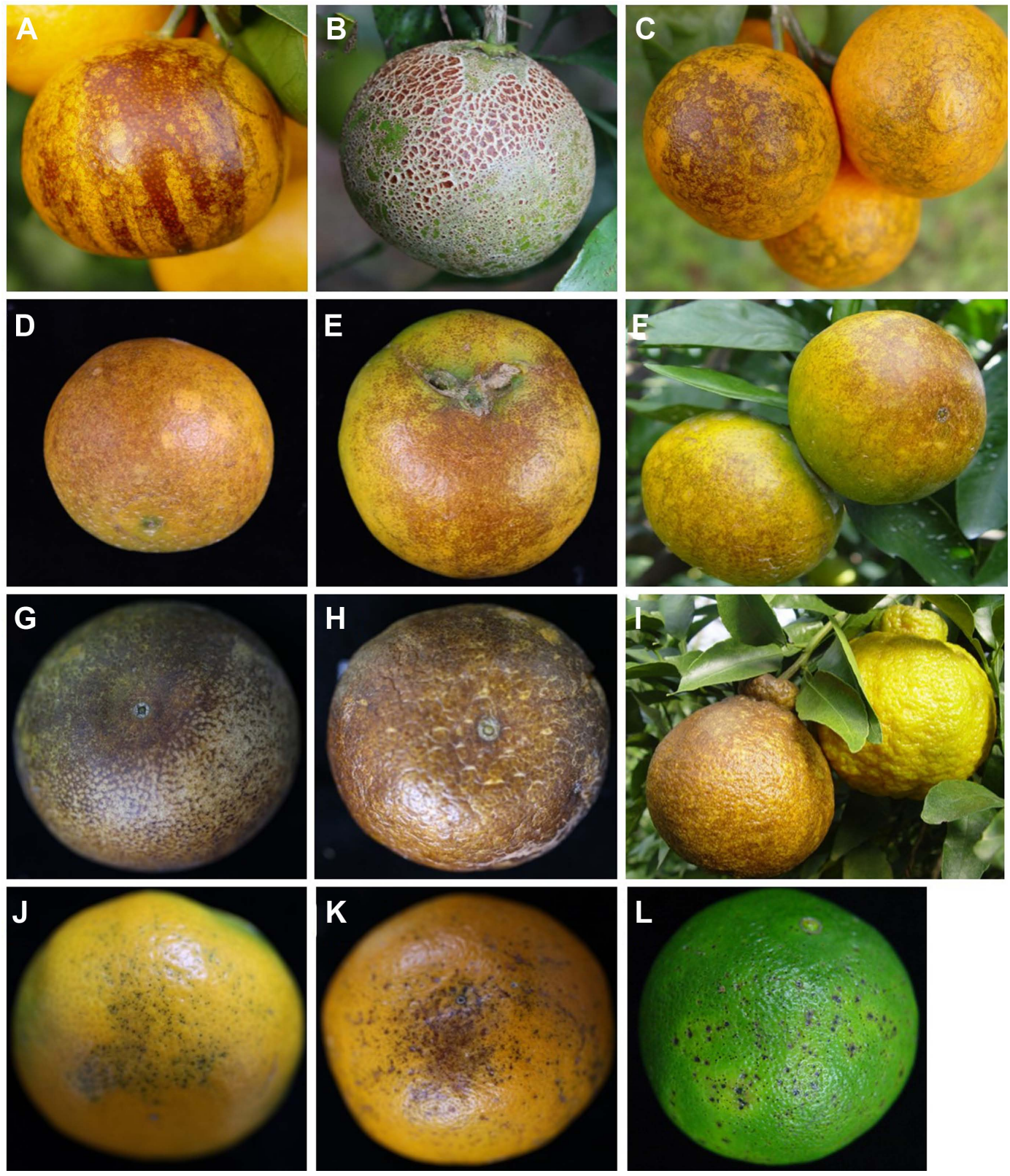

Fig. 2. Symptoms of citrus melanose and its similar symptoms on fruits. (A-C) Mudcake melanoses. (D-F) Scirtothrips dorsalis hood, yellow tea thrips. (G-I) Aculops pelekassi keifer rust mite. Damaged by sunscald (J, K) and zinc sprays (L).

Table 1. Sequence primers used in this study

\begin{tabular}{|c|c|c|c|c|c|c|}
\hline & & Sequence $\left(5^{\prime}-3^{\prime}\right)$ & Length & $\mathrm{Tm}$ & $\begin{array}{l}\text { Product } \\
\text { size (bp) }\end{array}$ & Reference \\
\hline \multirow[t]{2}{*}{ Dcitri } & $\mathrm{F}$ & GTTTAACTACTGCGCTCGGGGTCCTG & 26 & 62.8 & 388 & In this study \\
\hline & $\mathrm{R}$ & CTTACTGTTGCCTCGGCGCAGG & 22 & 62.8 & & \\
\hline \multirow[t]{2}{*}{ ITS } & $\mathrm{F}$ & TCCTCCGCTTATTGATATGC & 20 & 52.1 & 604 & White et al. (1990) \\
\hline & $\mathrm{R}$ & GGAAGTAAAAGTCGTAACAAGG & 22 & 51.3 & & \\
\hline
\end{tabular}

ITS, internal transcribed spacer. 
A
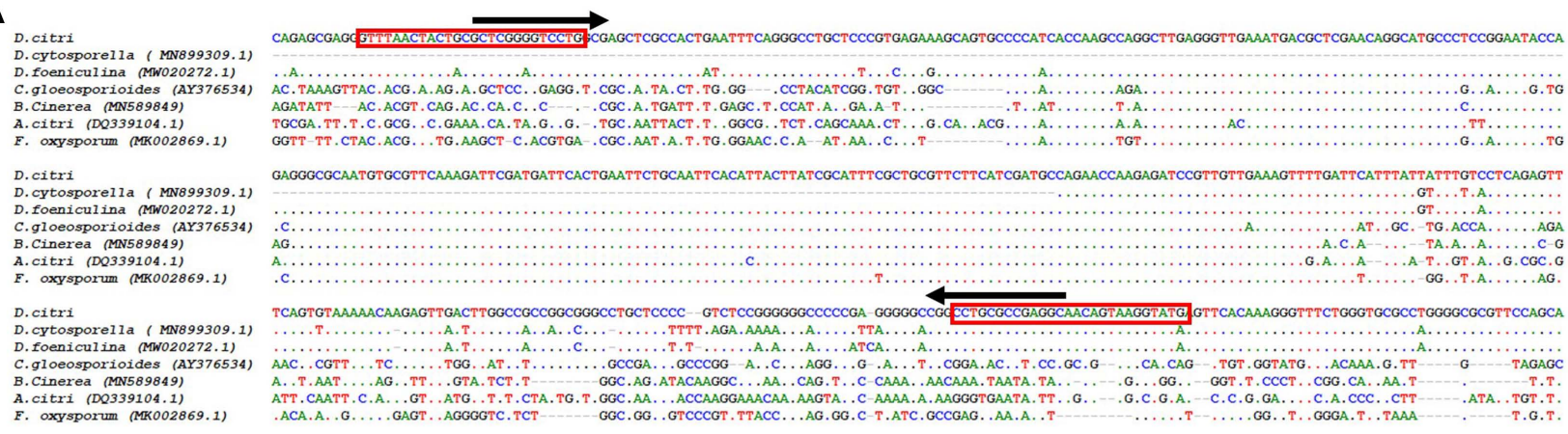

B

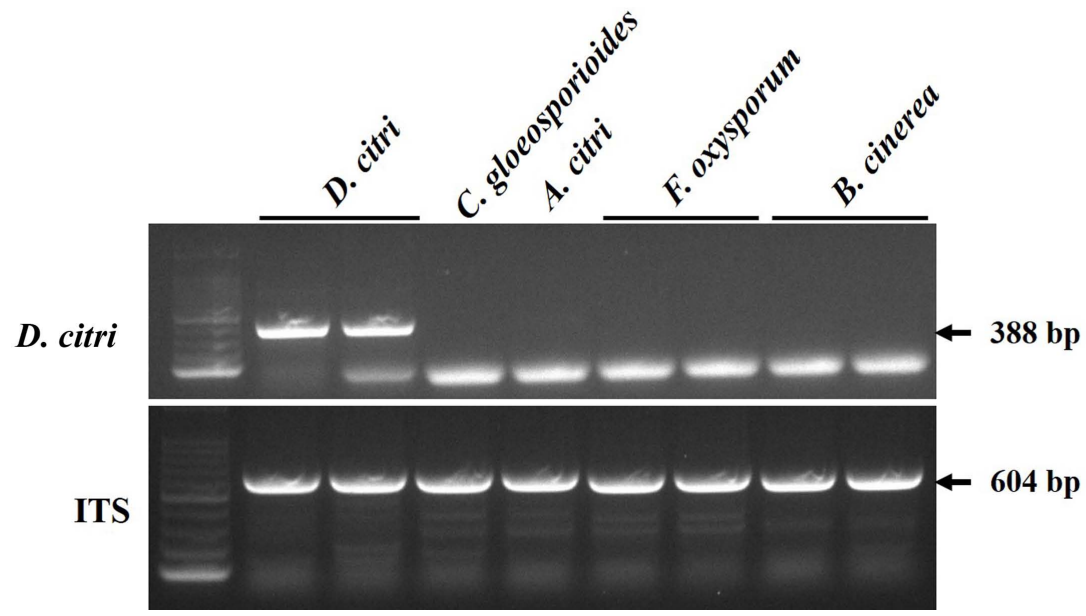

Fig. 3. Development of specific marker for detection of Diaporthe citri. (A) Alignment of internal transcribed spacer (ITS) sequence of Diaporthe citri, D. cytosporella (MN899309.1), D. foeniculina (MW20272.1), Colletotrichum gloeosporioides (AY376534), Alternaria citri (DQ339104.1), Fusarium oxysporum (MK002869.1), Botrytis cinerea (MN589849) and for designing D. citri specific primers. (B) Specific detection of D. citri from five isolates including C. gloeosporioides, A. citri, F. oxysporum, and B. cinerea. Lane M, 100bp DNA ladder; lanes 1 and 2, Diaporthe citri; lane 3, Colletotrichum gloeosporioides; lane 4, Alternaria citri; lanes 5 and 6, Fusarium oxysporum; lanes 7 and 8, Botrytis cinerea.

Kit (Invitrogen, Carlsbad, CA, USA). The plasmid was extracted using the QIAprep Spin Miniprep Kit (Qiagen) and sequenced. In addition, the ITS sequences of D. cytosporella (MN899309.1), D. foeniculina (MW020272.1), C. gloeosporioides (AY376534), B. cinerea (MN589849), A. citri (DQ339104.1), and F. oxysporum (MK002869.1) were obtained from the National Center for Biotechnology Information (NCBI). Five isolate sequences, including ITS of $D$. citri, were aligned using Bio-Edit software and then, Dcitri primers were designed with an area of $388 \mathrm{bp}$ (Table 1, Fig. 3A).

To evaluate the specificity of the Dcitri primers developed in this study, a PCR assay was performed. Total genomic DNA of five isolates, $D$. citri, $C$. gloeosporioides, $B$. cinerea, $A$. citri, and $F$. oxysporum were also used as templates. PCR was performed in a final volume of $20 \mu \mathrm{l}$ of reaction mixture using the Accupower Hotstart PCR pre-mix (catalog no. K-5051, Bioneer, Daejeon, Korea). The PCR reactions were carried out as follows: pre-denaturation for 3 min at $95^{\circ} \mathrm{C}, 40$ cycles of denaturation for $30 \mathrm{~s}$ at $95^{\circ} \mathrm{C}$, annealing for $30 \mathrm{~s}$ at $63^{\circ} \mathrm{C}$, extension for $30 \mathrm{~s}$ at $72^{\circ} \mathrm{C}$, and final extension for $10 \mathrm{~min}$ at $72^{\circ} \mathrm{C}$. The PCR products were electrophoresed on a $1.5 \%$ agarose gel, stained with GelRed nucleic acid $\times 10,000$ in water (Biotium, Fremont, CA, USA), and then visualized under UV light using a Davinch-Gel Gel Imaging System (Davinch-K, Seoul, Korea). The PCR assay confirmed that Dcitri primers amplified a specific product of $388 \mathrm{bp}$ in $D$. citri and not in other isolates, $C$. gloeosporioides, B. cinerea, A. citri, and F. oxysporum. The ITS primers, as an internal control, amplified a product of $604 \mathrm{bp}$ from five isolates (Fig. 3B).

To confirm whether specific products were amplified only in melanose symptoms caused by $D$. citri, PCR reactions were performed using Dcitri primers. Fruits with 


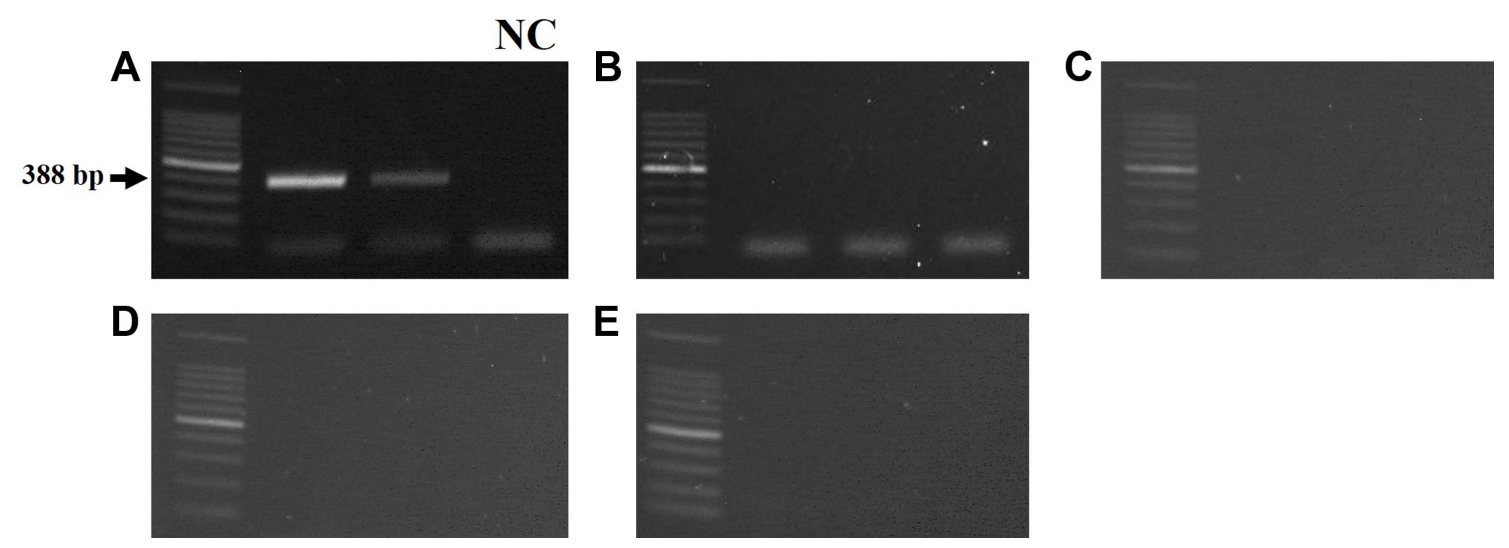

Fig. 4. Diagnosis results of citrus melanose disease from its similar symptoms using specific primers for Diaporthe citri. (A) Citrus melanoses diseases and no symptom control (NC, negative control). Damaged by sunscald (C), copper sprays (B), Scirtothrips dorsalis hood (D), and Aculops pelekassi keifer (E).

melanose symptoms and melanose-like symptoms, including copper spray, sunscald, and damage owing to yellow tea thrips and pink citrus rust mite, were collected and then, the lesion of each symptom on fruit rind was disinfected for $1 \mathrm{~min}$ in $75 \%$ ethanol and then $1 \mathrm{~min}$ in $1 \%$ sodium hypochlorite, followed by rinsing in sterile water and cutting with scalpel blades. Total genomic DNA was extracted as described previously. Specific amplified bands were observed in melanose-diseased fruits (Fig. 4A), whereas no products were amplified in melanose-like symptom fruits caused by copper-injury, sunscald, and damage owing to yellow tea thrips and pink citrus rust mite (Fig. 4B-E).

In addition, the lesions of melanose-like blemish known to be caused by $D$. medusasea on fruits of very early satsuma mandarin, which is smaller lesion size than that of melanose, were sampled from the open field of CRI (Supplementary Fig. 1A and B) and then analyzed using PCR. Similar to the result of melanose, specific products were observed in DNA extracted from melanose-like lesions (Supplementary Fig. 1C). This result is believed to be because $D$. medusaea, which causes disease in citrus, was reclassified into the same strain as $D$. citri. And, the ITS region for D. cytosporella (MN899309.1) and D. foeniculina (MW020272.1), which are reported to be found in citrus but do not cause disease in citrus in the Europe and California (USA), were collected from NCBI and compared with Dcitri primer. It is thought that the same products will be amplified from D. cytosporella (MN899309.1) and D. foeniculina (MW020272.1). However, since these strains have not yet been reported to be found in Korean citrus and do not directly cause disease, it is judged that these strains had not significant effect on distinguishing the melanose induced by $D$. citri from melanose-like symptoms induced by other factors. In conclusion, we developed Dcitri primers in this study and confirmed using PCR assay that the specific products were amplified in $D$. citri isolate and melanose symptoms caused by $D$. citri. It is expected that Dcitri marker will be useful in accurately diagnosing melanose caused by $D$. citri and distinguishing it from melanose-like symptoms.

\section{Conflicts of Interest}

No potential conflict of interest relevant to this article was reported.

\section{Acknowledgments}

This work was carried out with the support of the Research Program for the National Institute of Horticultural \& Herbal Science (Project No. PJ01506101), Rural Development Administration, Republic of Korea.

\section{Electronic Supplementary Material}

Supplementary materials are available at The Plant Pathology Journal website (http://www.ppjonline.org/).

\section{References}

Albrigo, L. G. and Grosser, J. W. 1996. Methods for evaluation of spray chemical phytotoxicity to citrus. Proc. Fla. State Hort. Soc. 109:52-57.

Barber, H. N. and Sharpe, P. J. H. 1971. Genetics and physiology of sunscald of fruits. Agric. Meteorol. 8:175-191.

Childers, C. C. and Achor, D. S. 1999. The eriophyoid mite complex on Florida citrus (Acari: Eriophyidae and Diptilomiopi- 
dae). Proc. Fla. State Hort. Soc. 112:79-87.

Gopal, K., Lakshmi, M. L., Sarada, G., Nagalakshmi, T., Sankar, T. G., Gopi, V. and Ramana, K. T. V. 2014. Citrus melanose (Diaporthe citri Wolf): a review. Int. J. Curr. Microbiol. Appl. Sci. 3:113-124.

Hyun, J.-W., Ko, S.-W., Kim, D.-H., Han, S.-G., Kim, K.-S., Kwon, H.-M. and Lim, H.-C. 2005. Effective usage of copper fungicides for environmental-friendly control of citrus diseases. Res. Plant Dis. 11:115-121 (in Korean).

Hyun, J.-W., Hwang, R.-Y., Lee, K.-S., Song, J.-H., Yi, P.-H., Kown, H.-M., Hyun, D.-H. and Kim, K.-S. 2012. Seasonal occurrence of yellow tea thrips, Scirtothrips dorsalis Hood (Thysanoptera: Thripidae) in citrus orchards and its damage symptoms on citrus fruits. Korean J. Appl. Entomol. 51:1-7 (in Korean).

Hyun, J.-W., Yi, P.-H., Hwang, R.-Y. and Moon, K.-H. 2013. Aspect of incidence of the major citrus diseases recently. Res. Plant Dis. 19:102-107 (in Korean).

Kwon, H.-M., Nam, K.-W., Kim, K.-S., Kim, D.-H., Lee, S.-C. and Hyun, J.-W. 2003. Characterization of the causal fungus of citrus melanose, Diaphorthe citri isolated from blighted twigs of citrus in Jeju. Res. Plant Dis. 9:153-158 (in Korean). Udayanga, D., Castlebury, L. A., Rossman, A. Y. and Hyde, K. D. 2014. Species limits in Diaporthe: molecular re-assessment of D. citri, D. cytosporella, D. foeniculina and D. rudis. Persoonia 32:83-101.

White, T. J., Bruns, T., Lee, S. and Taylor, J. 1990. Amplification and direct sequencing of fungal ribosomal RNA genes for phylogenetics. In: PCR Protocols: a guide to methods and applications, eds. by M. A. Innis, D. H. Gelfand, J. J. Sninsky and T. J. White, pp. 315-322. Academic Press, San Diego, CA, USA.

Whiteside, J. O. and Timmer, L. W. 2000. Melanose. In: Compendium of citrus diseases, eds. by L. W. Timmer, S. M. Garnsey and J. H. Graham, pp. 28-29. American Phytopathological Society, St. Paul, MN, USA.

Yi, P.-H., Hyun, J.-W., Hwang, R.-Y. and Kim, K.-S. 2014. Improvement of control efficacy of mancozeb wettable powder against citrus melanose by mixing with paraffin oil. Res. Plant Dis. 20:196-200 (in Korean). 